nature

\title{
November 18, 1976
}

\section{Don’t move!}

FOR many years commissions, committees, working parties and individuals have pondered the problem of the scientific civil servant and his or her career prospects. In the last year or two much of this thinking has been fuelled by concern (at least by those on the outside) that the civil servant, with a generally securer job and an excellent pension scheme, has also been paid considerably better than his counterpart elsewhere. But long before this became an issue many thinking people, by no means all outsiders, were worried that the scientific civil service lacked either enough right openings for mature scientists or any means of goading such scientists not to sit and fester within the service. The Bondi Task Force which reported in 1974 was the most recent group to look at the problem, and came up with proposals to increase mobility into and out of the service.

A small unit was set up in the Civil Service Department in 1972, initially to work with the Bondi Task Force but eventually to proceed under its own steam in stimulating mobility. Unfortunately, its terms of reference were limited. Many believe that the best way to stimulate a scientist to give of his best and the best way to encourage an organisation to make the best use of its manpower is for the employer to make it quite clear to the employee at the outset that no one can be promised forty years of continuous satisfying employment. Under these circumstances there could be a valuable trade at all levels of people into and out of the civil service.

But this is not to be-and at times like the present, when projects are being trimmed or cancelled, note how the civil and public servants remain while industrial contractors have to cope with redundancies. The unit which was established was not given the job of helping people to make major switches in career; it was given the much more timid mission of stimulating two-year (typically) secondments into and out of the service- but with a guaranteed return ticket. And even this relatively unadventurous project has hardly met with waves of enthusiasm, as a recently circulated progress report of the Scientists Interchange Unit makes clear.

It is difficult to estimate exactly how many within the service might in one circumstance or another be candidates for secondment, or on the other hand how many openings might arise which could be filled on a shortterm basis by outsiders. But there are 2,300 Principal Scientific Officers in the service, and if we include other grades above and below this level and some in the analogous technical officer grades there might be 5,000 who should at least know about the scheme.

Yet in the last three years only 23 made an approach to the unit, and of these only five could be found places outside-four in industry, one in a research council. In the same period 20 secondments were made into the service--nine from industry, ten from universities and one from a research council. It is only fair to add that government departments sometimes arrange their own secondments without going through the unit, and in the same three years 18 did an outward move (though less than half into industry) and nine an inward move (two from industry).

The picture, as the unit admits, is disappointing. There seems little enthusiasm for tasting another job even with all the safety of one's own job being kept warm. It would be easy to conclude that the average British scientist is feeble-minded and unenterprising. That may indeed be true, but it should be made clear that the present scheme is actually a much more tricky one to make successful, and maybe a much less attractive one than a one-way ticket scheme. Skills have to be closely matched, employers have to be convinced that loss of employees for two years is in their interests, petty jealousies over salaries have to be overcome, temporary accommodation and schooling has to be found if a move is necessary, the briefing period may be a significant fraction of the total time available and so on.

Permanent moves could not be more difficult and indeed might be very much easier for all concerned. Certainly without them the same old accusations will continue to be thrown at the civil service, and scientists will have achieved little on their side to facilitate the more open style of government for which many yearn and which requires more flow into and out of government establishments. The Bondi Task Force should reconvene to consider, even in a time of gloomy economic prognostications, whether it cannot push for more than just secondments. 